Vorzüge haben. Die mitgetheilten Belege zeigen, dass sich die gewogenen Niederschläge durch geeignete Reagentien wieder lösen lassen, ohne dass das Gewicht des Tiegels mit dem Filter sich ändert, so dass sich dasselbe Filter öfters wieder benutzen lässt.

In analoger Weise lassen sich aus geeigneten Verbindungen anderer Metalle schwammige Metallfilter herstellen, die unter Umständen gleichfalls gute Dienste leisten können.

Zur Prüfung der chemischen Reagentien auf Reinheit hat C. Krauch*) eine Zusammenstellung von Vorschriften veröffentlicht, auf welche ich nicht verfehlen will die Leser der Zeitschrift aufmerksam zu machen.

Der Verfasser war bestrebt einerseits die Anfordcrungen, welche von Seiten des Analytikers gestellt werden müssen, zu präcisiren und andererseits auch zu berücksichtigen, in wie weit die Technik im Stande ist, Präparate von bestimmter Reinheit zu liefern, und er hat die Methoden auf Grund praktischer Erfahrungen in beiden Richtungen hin ausgearbeitet. Er hat dabei weiter in's Auge gefasst, dass die Prüfungen, auch bei nach verschiedenartigen Verfahren dargestellten Präparaten eine sichere Beurtheilung der Beschaffenheit der Reagentien ermöglichen sollen, und macht schliesslich auf die am häufigsten sich findenden Verunreinigungen der einzelnen Körper aufmerksam.**)

Auch Chas. O. Curtman***) hat eine ausführliche Arbeit über die Anwendung, Prüfung und Herstellung der Reagentien zu veröffentlichen begonnen, auf welche ich hier nur hinweisen kann.

Zur Anwendung des Wasserstoffhyperoxyds zu analytischen Zwecken. F. P. Dunning ton $\dagger$ ) empfiehlt, um die Auflösung höherer Oxyde von Metallen, welche sich in verdünnten Säuren nicht leicht lösen, zu beschleunigen, einen Zusatz einiger Tropfen von Wasserstoffhyperoxydlösung zu machen, wodurch die Auflösung unter Sauerstoffentwicklungleicht erfolgt. Namentlich hebt der Verfasser herror die Auflösung von Bleihyperoxyd in verdünnter Salpetersäure, diejenige von Niederschlägen,

*) Die Prüfung der chemischen Reagentien auf Reinheit von Dr. C. Krau ch mit einem Vorwort von Prof. J. König, Darmstadt, Verlag von L. Brill 1888. **) Die chemische Fabrik von E. MI e r ck in Darmstadt, auf deren Veranlassung der Verfasser das Schriftchen ausgearbeitet hat, wird von jetat ab die Reinheit der Reagentien entsprechend den von $\mathrm{Krauch}$ angegebenen Normen garantiren.

***) The Druggist 1888; vom Verfasser eingesandt.

†) Journal of analytical chemistry 2, 390 . 
welche durch Ammoniak erzengt sind und im wesentlichen aus Thonerdeund Eisenoxydhydrat bestehen, in verdünnter Salzsäure. In letzterem Falle wird nämlich, wenn etwas Manganoxyd beigemengt ist, dieses der Einwirkung der Salzsäure widerstehen, was bei Zusatz von Wasserstoffhyperoxyd vermieden wird.

Auch die geglühten Oxyde des Cers und Mangans lösen sich bei Gegenwart von Wasserstoffhyperoxyd leicht in kalten verdünnten Säuren.

C. F. Göhring*) schlägt vor, das Wasserstoffhyperoxyd zur Herstellung von Sauerstoff zu benutzen, indem man übermangansaures Kali auf dasselbe einwirken lässt. Der Verfasser empfiehlt eine Entwicklungsflasche, deren Kork einen Tropftrichter und ein Gasableitungsrohr trägt, mit der käuflichen etwa 3 procentigen Lösung halb anzufüllen, mit ein paar Tropfen Ammoniak zur Abstumpfung der Säure zu versetzen (wobei gewöhnlich Trübung eintritt) und ans dem Tropftrichter eine kleine Menge Permanganatlösung (etwa $5 c c$ einer Lösung von $3 g$ im Liter) einfliessen zu lassen und umzaschütteln. Wünscht man eine stärkere Entwicklung, so nimnt man etwas mehr Permanganat. Die Entwicklung ist gleichmässig und kann so lange durch Einfliessenlassen des übermangansauren Kalis immer wieder in lebhaften Gang gebracht werden, als noch Wasserstoffhyperoxyd vorhanden ist. Dass dies nicht mehr der Fall, zeigt sich dadurch, dass eine angesäuerte Probe der Flüssigkeit die Permanganatfärbung erkennen lässt.

Aus $100 c c$ der käuflichen Wasserstoffhyperoxydlösung lässt sich etwa $1 l$ Sauerstoff erhalten, der eventuell vor der Verwendung mit Schwefelsäure gewaschen and getrocknet werden muss.

\section{Auf das Vorkommen von Eisenoxydul enthaltendem Rhodankalium} macht J. Kranzfeld ${ }^{* *}$ ) aufmerksam. Dasselbe färbt sich an der Luft durch Oxydation roth und ist überhaupt zum Eisennachweis nicht anwendbar, Es kann leicht durch Auflösen in wässrigem Weingeist, Zufügen einiger Tropfen Schwefelammonium und Filtriren vom Eisen befreit und eventuell durch Eindampfen und Auskrystallisirenlassen wieder in fester Form gewonnen werden.

Zur Bereitung haltbaren Stärkekleisters für jodometrische Zwecke empfiehlt G. Gastin $\mathrm{e}^{* * *}$ ) $5 \mathrm{~g}$ Kartoffelstärke mit $1 \mathrm{cg}$ Quecksilberjodid

*) Chemikerzeitung 12, 1659.

**) Pharmaceutische Zeitschrift für Russland 28, 68.

***) Bull. soc. chim. 50, 172. 